\title{
AMITĀBHA BUDDHA REVISITED: INTO THE TWENTY- FIRST CENTURY MODERN SCIENCE
}

\author{
Ph.D. B. Hyun Choo', M.D.DABPM. Jay J. Choi', \\ "Stony Brook University, Stony Brook, NY". \\ Formerly UMD New Jersey Medical School, Newark, NJ. ${ }^{2}$ \\ U.S.A. \\ E-mail: bhyunchoo@gmail.com \\ doctorjaychoi@yahoo.com
}

\begin{abstract}
Buddhism and quantum physics share many points of contact. New scientific evidence regarding nonlocality has made possible an insightful understanding of nonduality and wholeness. In light of this discovery, modern intellectuals may become comfortable with the Mahāyanna concept of Buddha's meritorious qualities. Particularly, Amitābha Buddha symbolizes the Buddha of Infinite Light and Infinite Life, representing the transcendence of time and space. Specifically Amitābha signifies both wisdom and compassion, while the field of quantum mechanics reflects sufficiently the wisdom aspect of Amitäbha. However, compassion has not been incorporated in science due to its non-objective nature. Can modern intellectuals understand the wisdom comfortably to encompass compassion? This article develops and employs a novel conceptual approach to address a broader understanding and acceptance of modern science for scholars of religion. We argue that the concept of nonlocality, with its extension into a sequence of nonlocality-nonduality-wholeness, enables Amitäbha's wisdom and compassion to fit reasonably within the framework of modern science. Thus, Amitābha Buddha can be said to re-appear with a scientific face in the $21^{\text {st }}$ century.
\end{abstract}

Keywords: Amitābha Buddha; Buddhism; Quantum Physics; Nonlocality nonduality wholeness;

\section{INTRODUCTION}

In 1936 when Phyllis Wright, a six-grade student in the Sunday school of the Riverside Church in New York, asked Einstein whether scientists pray, and if they do, what they pray for, Einstein replied:

"Scientific research is based on the assumption that all events, including the actions of mankind, are determined by the laws of nature. Therefore, a research scientist will hardly be inclined to believe that events could be influenced by a prayer, that is, by a wish addressed to a supernatural Being. However, we have to admit that our actual knowledge of these laws is only an incomplete piece of work, so that ultimately the belief in the existence of fundamental all-embracing laws also rests on a sort of faith.... The pursuit of science leads therefore to a religious feeling of a special kind, which differs essentially from the religiosity of more naïve people" 1

\footnotetext{
${ }^{1}$ Max Jammer, Einstein and Religion: Physics and Theology, Princeton University Press, Princeton, NJ., 1944, pp. 92-93.
} 
This ingenuous question is still valid today and retains its original strength. However, how can we reconcile the scientific assumption or belief with a religious faith? Amitābha Buddha, for example, venerated by Mahāyāna Buddhists, is the common name of the Buddha of Infinite Light and Infinite Life, thus transcending the classical sense of time and space. Although this concept of transcendence is often spoken about and sounds so simple due to its familiarity, it is a difficult concept to grasp, especially the idea of "eternal present" and the "here and now." It has traditionally been more readily understood from a philosophical, rather than a scientific, perspective. However, a number of concepts from quantum mechanics have helped it emerge from its elusive nature to a more accessible one.

At the noumenon or intuitive level, Amitābha Buddha is said to represent the True Mind/One Mind, that is, the Self-nature of Buddhas and all sentient beings. At the scriptural level, Amitābha Buddha is trans-historical, that is, the Buddha of the Western Paradise and venerated particularly in Pure Land Buddhism. Pure Land Buddhism propounds a variety of practices including meditation on images and awareness, the use of mantras and prayer, and rhythmic chanting the name of Amitābha. The recitation of Amitābha Buddha's name, that is, Namu Amitabul or Namo Amitābha Buddha, is an important practice performed by Pure Land Buddhists who wish to seek rebirth in Sukhāvatī, the Western Bliss Land where Amitābha Buddha is said to reside. A recitation of such simple repetitive words may seem an uneducated, perhaps illiterate practice, yet it is often performed among common lay Buddhists. They believe that the practice of this mantra may help them tolerate a multitude of personal harsh conditions and also prevent them from succumbing to worldly desires. It appears that this unsophisticated, recitative ritual may insinuate a lack of intelligence. For this very reason, and as a consequence, the tendency to focus on one's own subjective and personal religious experience has generally been disparaged in the classical scientific arena, specifically the Cartesian and Newtonian dualistic space and time world-view. Such worldview has been heretofore powerfully influential in today's society within the frame of positivistic-reductionistic-objective (PRO) formalism. Thus, discussion of subjective issues has often been classified as non-scientific within the realm of so-called mainstream scholars of philosophy and religion; the concept of religiosity has been not only discredited but also often discarded from the academic arena. However, we aim to discuss how this approach, that is, the use of recitation, can be interpreted in a positive sense using modern scientific principles and rational insights. Interestingly, the advent of the new modern physics, which is more organic and holistic, has opened a new window to allow for a radically different scientific interpretation of the phenomena of mind and religiosity, facilitating an opportunity for meaningful dialogue. It has been demonstrated that the classical world-view has been essentially overturned by the new modern physics - a useful tool for reinterpreting reality and the phenomena of mind. However, it appears that students of humanity have been persistent in their efforts to depict the truth in the classical methodology, which narrows itself to explaining phenomenon solely through reference to physical and objective causes of the PRO kind. Specifically, Newtonian physics is described as uncompromised dichotomy and stresses an either/or vision of truth. In contrast, quantum reality and human nature are situational or context-dependent, utilizing the concept of both/and and embodying the realm of quantum holism. ${ }^{2}$ This is to be elaborated further in this article. For Mahāyāna Buddhists, enlightenment may be elucidated as the full awareness of an inexpressible śünyatā, or

\footnotetext{
${ }^{2}$ Ian Marshall and Zohar Danah, Who's Afraid of Schrödinger's Cat? William Morrow \&Co., NY., 1997, pp. 299-300.
} 
emptiness of essence, which transcends dualistic reality. This distinctive awareness reflects a fully enlightened state, which is said to be completely devoid of delusion. Curiously, quantum reality and śünyata may be addressed as sharing similar reality principles, in that the quantum vacuum is not merely empty but replete with the potentiality of encompassing everything in the universe, while the Buddhist concept of śünyatā denotes a similar view, as expressed in the phrase "wondrous existence of true emptiness." This state is attained when all forms of existence and phenomena are observed in their real nature.

Quantum reality, as explained in the wave/particle dualism of micro-entities, appears to be a paradox based on everyday experience, as particles and waves presume to be fundamentally different types of entities. The classical Newtonian perspective indicates that no particle can be a wave, any more than a single object can be both a bullet and a ripple. Yet, in the view of quantum physics, electrons are demonstrated to display both particle and wave characteristics; the waves and particles themselves can transmute into each other. This is familiarly understood in Buddhism as "neither one, nor two" or "neither the same nor different." This expression signifies a distinct Buddhist way of characterizing the relationship between various kinds of phenomena. It is often introduced as a Mādhyamika view, but is found in almost every branch of Mahāyāna Buddhism.

Quantum Field Theory (QFT), an extension of quantum theory into the realm of highenergy physics, goes further denoting in which no atoms or particles are regarded as primary or permanent, but rather as patterns of dynamic energy, that is, the quanta or excitations of some underlying vibrating field. There is general agreement among modern scientists that QFT is the most accurate physical theory to date, being accurate to about one part in about $10^{11}$, that is, one hundred billion, while general relativity has been tested to be correct to one part in $10^{14}$, or one hundred trillion. ${ }^{3}$

Experiments in particle physics show that existing particles are coming and going from "nowhere," as though something were acting on them. Concerning this issue, particle physicists may puzzle over the riddle of a fundamental quest: As particles can appear and disappear at random, what do they emerge from and where do they go ${ }^{4}$ Scientists are often reluctant to step further into a non-scientific arena, which may raise religious or philosophical issues. Marshall \& Zohar write, "The greatly expanded mathematical framework of QFT attributes such effects to an all-pervasive, underlying field of potential the vacuum." Unseen and not directly measurable, the vacuum exerts a subtle push on the surface of existence, like water pushing against things immersed in it. This is known as the "Casimir effect" in QFT. ${ }^{5}$ The Casimir effect refers to the understanding that the universe is not filled with the vacuum, but rather it is written on or emerges out of it. The quantum vacuum, then, is said to be the background of evanescent reality, which is the ground state of energy in the universe and called as such because it cannot be perceived or measured directly. Another line of thought attributed to QFT suggests that all existence may be described as an excitation of the underlying quantum vacuum, that is, all existing things are like ripples on a universal pond, rather than being seen as solid, individual lumps. The universe is thus described as consisting of so many patterns of dynamic energy. ${ }^{6}$ Interestingly, this is intuitively evocative of the transcendent nature of Amitābha Buddha.

\footnotetext{
${ }^{3}$ Roger Penrose, "Quantum Theory and Spacetime", in The Nature of Space and Time, (ed.), by Stephen Hawking, and Roger Penrose, Princeton University Press, Princeton \& Oxford, 1996, p. 61.

${ }^{4}$ Ian Marshall and Zohar Danah, Who's Afraid of Schrödinger's Cat? p. 304.

${ }^{5}$ Ibid., p. 303.

${ }^{6}$ Ibid., p. 185.
} 
The notion of transcending time and space can therefore reasonably be understood from a scientific perspective as propounding "eternal present, and the here and now." In the noted Buddhist work entitled "The Awakening of Faith" a more specific analogy is illustrated in which ripples are explained as an inseparable product of the activity of the wind on the water in a pond, the wet nature remaining undisturbed. ${ }^{7}$ Likewise, mind is stirred by the wind of ignorance. Aśvaghosha, the author attributed to this work, expounds:

\begin{abstract}
"All modes (lakshana) of mind and consciousness are ignorance. Ignorance does not exist apart from enlightenment; therefore, it cannot be destroyed, and yet it cannot not be destroyed. This is like the relationship that exists between the water of the ocean [namely, enlightenment] and its waves [modes of mind] stirred by the wind [ignorance]. Water and wind are inseparable; but water is not mobile by nature, and if the wind stops, the movement ceases. But the wet nature remains undestroyed. Likewise, man's mind, pure in its own nature, is stirred by the wind of ignorance. Both Mind and ignorance have no particular forms of their own, and they are inseparable. Yet Mind is not movable by nature, and if ignorance ceases, then the continuity [of deluded activities] ceases. But the essential nature of wisdom [namely, the essence of Mind, or the wet nature of the water] remains undestroyedThis logos-principle, though hidden and accessible only to intelligence, is still material, as it results from the identification of the heroclitian logos with cosmic fire". 8
\end{abstract}

Building from these ideas, the transpersonal nature of Amitābha Buddha's Infinite Light and Infinite Life may reasonably be perceived as a resonance between qualities of the quantum vacuum and human reality, that is, the underlying ground-energy state of the universe as demonstrated by QFT and related qualities of human reality. In this regard, quantum mechanics, which advocates the quantum model of reality, may be inductive in allusion to Amitābha's Western Paradise for today's modern scientific-minded individuals. However, it should be acknowledged that the element of compassion has yet to enter the debate in the quantum mechanics. On this premise, we seek to examine a series of critical issues and suggest some insights drawn from modern scientific perspectives:

1. Can one understand the transcendent nature of Amitābha Buddha within a framework of modern scientific interpretation?

2. Can the recitation of Amitābha Buddha be practiced comfortably by scientifically minded intellectuals toward Einstein's "religious feeling of a special kind" or an enlightenment of the Buddhist kind?

This article develops and employs a novel conceptual approach to this question. We argue that the concept of nonlocality, with its extension into a sequence of nonlocalitynonduality- wholeness, enables Amitābha's wisdom and compassion to fit reasonably within the framework of modern science. In order to understand the role of interpenetration regarding both disciplines, we will first explore how the nature of reality can be understood in both Buddhism and modern science, particularly in quantum physics. Secondly, a relevance will be posited between Buddhism and quantum physics with regard to ultimate reality, illuminating the nature of Amitābha Buddha and how the practice of recitation of his name can possibly lead one to an enlightenment of the Buddhist kind. Thirdly, we will elaborate on how this approach can contribute toward introducing the issue of personal religious experience and/or the phenomena of religiosity into the Buddhist studies academia.

\footnotetext{
${ }^{7}$ Robert E. Buswell, Jr., and Donald S. Lopez, The Princeton Dictionary of Buddhism, Princeton University Press, Princeton, NJ., 2014, p. 76.

${ }^{8}$ Yoshito S. Hakeda, (trans.), The Awakening of Faith; Attributed to Aśvaghosha, Columbia University Press, New York \& London, 1967, p.41.
} 


\section{WHO IS AMITĀBHA BUDDHA?}

Amitābha Buddha is described as the Buddha of Infinite Light and Infinite Life, and is also known as one of the Five Wisdom Tathägatas. ${ }^{9}$ The Wisdom Buddhas are all aspects of the Dharmakaya or "Dharma-body," which embodies the principle of enlightenment. As a trans-historical Buddha venerated by all Mahāyāna schools and particularly the Pure Land School, Amitābha in peaceful meditation is said to preside over the Sukhāvatī, or Western Pure Land, where anyone can be said to be reborn through sincere recitation of his name, "Namo Amitābha Buddha," particularly at the time of death. The basic doctrines concerning Amitābha and his vows are found in the Three Pure Land Sütras consisting of three canonical Mahāyāna texts: the Larger Sukhāvatīvyūha Sütra, the Sūtra of Immeasurable Life; the Sütra of the Meditation on the Buddha of Immeasurable Life; and the Smaller Sukhāvatīvyūha Sütra, the Smaller Sūtra on Amitāyus. According to the Larger Sütra, Amitābha was, in very ancient times and possibly in another realm, a monk named Dharmakāra. In some versions of the sūtra, Dharmakāra is described as a former king who, having come into contact with the Buddhist teachings, renounced his throne. He resolved to become a Buddha and so to come into possession of a Buddha-field (Buddha-ksetra; a world produced by the Buddha's merit) and possessed of many perfections through firm resolutions. These resolutions are expressed in his Forty-eight vows, which reflect the type of Buddha-field that he aspired to create (the conditions under which beings might be born into that world). Among his Forty-eight vows, the eighteenth vow is that any being in any universe desiring to be born into Amitābha's Pure Land and calling upon his name even as few as ten times would be guaranteed rebirth there. His nineteenth vow promises that he, together with his bodhisattvas and other blessed Buddhists, would appear before those who calls upon him at the moment of death. ${ }^{10}$ Through his efforts, Dharmakāra, known as Amitābha, is said to have created the Pure Land, called Sukhāvatī in Sanskrit, which means "possessing happiness." Sukhāvatī is said to be situated in the uttermost west, beyond the bounds of our conventional world. By the power of his vows, Amitābha has made it possible for all who call upon him to be reborn in this land, there to undergo instruction by him in the Dharma and ultimately to become bodhisattvas and Buddhas. This openness and acceptance of all kinds of people have made the Pure Land school one of the major influences in Mahāyāna Buddhism. It has become popular in northwest India/Pakistan and Afghanistan, and has further spread to Central Asia, China, Korea and Japan.

The sutra goes on to explain that Amitābha, after accumulating great merit over countless lives, finally achieved Buddhahood and is still alive in his land of Sukhāvatī, whose many virtues and joys are described. The name Amitābha is a compound of the Sanskrit words amita ("without bound" or "infinite") and $\bar{a} b h \bar{a}$ ("light" or "splendor"). Consequently, the name is to be interpreted as "one who possesses infinite light without bound." The name Amitayyus is also used; this is a compound of amita and ayus ("life"), and so means "one whose life is boundless." Therefore, he is seen as the supreme power and energy of nature, cast on an earthly plain, and accessible to all sentient beings. In Tibetan Buddhism, Amitābha is red in color, being the color of love, compassion, and emotional energy. His direction is to the west and so he is envisioned as the (red) setting sun. During sunset, the sun is gentle and one can look directly into its fierce power, without coming to

\footnotetext{
9 Five Dhyani Buddhas. In Vajrayana Buddhism, the Five Dhyani Buddhas, the Five Great Buddhas and the Five Jinas (S. for "conqueror" or "victor"), are representations of the five qualities of the Buddha.

${ }^{10}$ F. Max, Müller, "The Larger Sukhāvatī-vyūha, Buddhist Mahāyāna Texts", in The Sacred Books of the East, Vol. xlix, (trans.) by F. Max Müller, Dover Publications, Inc., Mineola, NY, 1969, pp. 12-22.
} 
any harm. When represented on a stupa, he always faces the west. Amitābha Buddha, similar to Shakyamuni Buddha, often appears as part of a triad: Avalokiteśvara on the left represents Amitābha's great compassion; and Mahāsthāmaprāpta on the right represents Amitābha's wisdom. Avalokiteśvara refers to the Lord who gazes and hears the Sounds of the World, also known as the Great Bodhisattva of "A Thousand Eyes and A Thousand Hands," who is said to see and help thousands everywhere and instantaneously. Mahāsthāmaprāpta refers to the Lord who is possessed of great power and believed to open people's eyes to the need to strive for awakening. Avalokiteśvara's unique emblem is the lotus, and is thus associated with its attributes: gentleness, openness, and purity. Amitābha's mount is the peacock, which is said to be capable of swallowing poisonous snakes without being harmed. In fact, the peacock is believed to derive its rich plumage from the poison of the snakes on which it feeds. This symbolism, of being immune even to poison and transmuting it into beauty, imparts a sense of the purifying and transforming power of Amitābha. Here, one may wonder if this nature of Amitābha, conveyed from a fictional story, can possess any meaningful realistic value in modern terms. For a religious person, the answer may easily be affirmative due to his/her personal belief, but how can scientifically minded intellectuals understand the Amitābha of "Infinite Light and Infinite Life" within the framework of a logical mind-set and consequently learn to act with a compassionate heart? This article endeavors to elaborate and employ a novel conceptual approach to this question.

\section{REALITY AS AN ILLUSION}

In formulating an answer to this question, one of the fundamental questions to be asked would be "What is true reality?" from both a religious and a scientific perspective. While comprehensive critical evaluation of this subject remains beyond the scope of this article, a brief explanation of the main theme may suffice here. Doctrine of emptiness or voidness, stressed in many Mahāyāna scriptures, is first propounded with the Perfection of Wisdom (Prajñāpāramitā) sūtras and the Mādhyamika school of Mahāyāna philosophy. ${ }^{11}$ Emptiness signifies the lack or absence of intrinsic nature in all phenomena, the final nature of all things. It goes beyond the early Buddhist position of anatta (non-Self) and refers to the understanding that all existence is based solely on dependent origination, that is, our perception of reality is an illusion; a falsely imagined type of existence dependent upon other conditions. To argue that all dharmas are empty does not mean that they do not exist, but rather identifies them as appearances, which should not be perceived as objects of grasping, expressed as śunyatā or emptiness. This is considered as the single most important Mahāyāna innovation.

None the more, modern quantum physicists, equipped with an accuracy of one part in 100 billions, have begun to corroborate this Buddhist notion of reality in which the objective existence of the world is seen as an illusion. In recent years, Buddhism has been at the center of inner science of mind, and much discussed in an ongoing working of the mind among both Buddhists and scientists. In particular, His Holiness the Dalai Lama has actively engaged in mind and life dialogues, which explore the wealth of scientific research in collaboration with Buddhism. ${ }^{12}$ Our ordinary experiences operate from the assumption that the objective world is real; we instinctively feel no hesitancy in asserting this undeniable

\footnotetext{
${ }^{11}$ Charles S. Prebish, Historical Dictionary of Buddhism; Historical Dictionaries of Religions, Philosophes, and Movements, The Scarecrow Press, Inc., Metuchen, N.J., \& London, 1993, p. 249.

12 The Dalai Lama, Herbert Benson, Robert A.F. Thurman, Howard E Gardner, and Daniel, Goleman, MindScience: An East-West Dialogue, Wisdom Publications, Boston, MA.,1991.
} 
belief. Specifically, classical Newtonian science has emphasized a third-person examination of a so-called "positive, reductionistic and objective" world-view, which is claimed to be scientifically true. From the perspective of classical science, one can empirically comprehend reality based on the five senses of seeing, hearing, smelling, tasting, and touching. This becomes the basis for a dualistic world-view, reflected in such terms as subject/object, mind/matter, wave/particle, life/death, long/short, clean/dirty, good/evil, and so on. However, the explanation of reality from this empirical view is obviously limited because the five senses have their own limitations. For instance, since visible light is known to comprise less than about $10 \%$ of the spectrum, it can be reasonably said that humans may see approximately $10 \%$ of the totality of reality. What is lurking around in the other $90 \%$ of the non-visible light world that we cannot see? While visual sense-based perception makes up merely $10 \%$ of the total reality, other senses may possess a similarly limited scope. Undeniably, humans sense only a small portion of the entirety of any given object. However, the issue of illusion in Buddhism surpasses beyond this $10 \%$ limitation. From the Buddhist perspective of śunyatā, even the $10 \%$ of the total sensible reality itself is said to be an illusion. What would be the quantum physicist's view on this?

According to quantum physicists, the reality which is based upon the five sense perceptions alone may not be a true reality, not only because of its limitation, but also because personal beliefs act as a filter and human perception creates nothing more than an illusion micro-macroscopically. Quantum physics describes physical reality on the most fundamental level in terms of exchange of quanta. In the development of quantum physics, Niels Bohr's realization of the fact that a quantum exists as both wave and particle was revolutionary. He stated that the wave aspect of a quantum is continuous and spread out over space and time, whereas the particle aspect is localized at one point in space and time. ${ }^{13}$ More precisely, it has been demonstrated that the wave is not actually spread out as a wave, but rather only a probability of the particle's existence is said to spread out as a wave; thus it is called the "probability wave."14

According to Bohr, when a measurement or observation occurs, the wave function "collapses", a possibility gives way to an actuality, and the wave becomes instantly realized as a particle. Marshall \& Zohar assert the fact, that the measurement or observation can so radically change the character of physical reality in a so-called superposition of possibilities, is the single most outstanding discovery of modern physics. ${ }^{15}$ Humans experience the world as "either/or", which Newton's classical mechanics describes as one's orientation in the physical world. However, quantum reality describes a bizarre world of "both/and": waves and particles; both here and there; now and then, and so forth. For these reasons, some physicists, who have not (?) yet penetrated a "scientific" insight from nonlocality encompassing into nonduality, believe that quantum theory may be incomplete. Nadeau and Kafatos ${ }^{16}$ commend Niels Bohr for the complementarity principle as the "logic of nature" that best describes the new relationship between parts and wholes in both physics and biology. This principle was originally developed by Bohr in an effort to explain waveparticle dualism in quantum physics. His Principle of Complementarity shows that the

\footnotetext{
${ }^{13}$ Robert Nadeau, and Menas Kafatos, The Non-Local Universe: The New Physics and Matters of the Mind, Oxford University Press, New York, 1999, p. 13.

${ }^{14}$ Sung K. Kim, and Y.G. Cho, Modern Physics explains Ban Ya Sim Gyung, Bulgwang Publishing Co., Seoul, Korea, 2006, p.78.

${ }^{15}$ Ian Marshall and Zohar Danah, Who's Afraid of Schrödinger's Cat? p. 222.

${ }^{16}$ Robert Nadeau, and Menas Kafatos, The Non-Local Universe, p. 13.
} 
materialistic common sense notion of reality is an illusion; the objective existence of the world is a mere projection as only one aspect of the particle. Bohr argued that many things are mutually exclusive, yet complementary: thought and action, subjectivity and objectivity, feeling and reasoning, and so forth. Nadeau and Kafatos assert that Niels Bohr and Werner Heisenberg recognized quite well that quantum theory would have a profound impact on our understanding of reality. Both physicists are considered the creators of quantum mechanics, the most precise and far reaching physical theory ever devised, which is viewed as the cornerstone of modern physics. Bohr says in his Philosophical Writings:

"As our knowledge becomes wider, we must always be prepared. . . to expect alterations in the point of view best suited for the ordering of our experience". 17

Heisenberg clarifies in his Physics and Philosophy: The existing scientific concepts cover always only a very limited part of reality, and the other part that has not yet been understood is infinite. Whenever we proceed from the known into the unknown... we may have to learn at the same time a new meaning of the word 'understanding'. ${ }^{18}$

Interestingly, the second century Buddhist philosopher Nagarjuna described a similar idea: "The ultimate reality is unmade; it will never be other than what it always is". ${ }^{19}$ Both Buddhists and quantum physicists make a strikingly similar claim; that the objective world is an illusion. However, one must note that physicists assert "neither existence" while Nagarjuna emphasizes "nor non-existence" as well. Thus, the Middle Way in Buddhism declares a state of "wondrous existence of true emptiness." However, in quantum mechanics, the element of compassion, which is so vital to Buddhist thought, is not yet an agenda which is agreed upon as part of science. Can modern intellectuals understand the wisdom comfortably to encompass compassion? This article investigates and employs a novel conceptual approach to this question.

From primeval times up to the present, human beings have had an innate obsession for fixated beliefs, one of which is "seeing is believing." This obstinacy regarding the foundational value of seeing reflects an inborn ignorance, which is the fundamental basis of the three poisons of sentient beings as pointed out by the Buddha. In order to transcend the level of ordinary experience from a world of the Newtonian "either/or" to a realm of the quantum "both/and", one must make a quantum leap from distinction knowledge to the wisdom of prajna. It may be far-fetched to connect any Buddhist principle too closely with any particular understanding of physics, but when meaningful comparisons and connections are made at a logical and philosophical level, an insightful dialogue between Buddhism and science can occur. Quantum mechanics may serve as a pivoting reference point for that purpose. In this regard, Niels Bohr may well be referred to as a Zen master of modern physics!

\section{AN UNPRECEDENTED CHALLENGE: A CONCEPT OF NONLOCALITY}

A quintessential discovery in quantum mechanics supports the view that physical reality may be arguably nonlocal. Classical physics since Descartes portrays the opposing view that physical reality is local, which means that a measurement at one point in space cannot influence what occurs at another beyond a fairly short distance. Descartes was known

\footnotetext{
${ }^{17}$ Niels Bohr, The Philosophical Writings of Niels Bohr, Ox Bow Press, Woodbridge, CT.,1987, p. 1.

${ }^{18}$ Werner Heisenberg, Physics and Philosophy: The Revolution in Modern Science, Harper \& Row, Publishers, NY, 1958, p. 201.

${ }^{19}$ K. Venkata Ramanan, Nagarjuna's Philosophy: As Presented in the Maha-Prajnaparamita-Sastra, Motilal Banarsidass, New Delhi, India, 1966, p. 268.
} 
to be among the first to assert that mind or consciousness appears to exist in a realm separate from matter, formalizing a duality between mind and nature. Until recently this has been perceived as an immutable truth. However, the amazing new aspect of nature known as nonlocality has posed an unprecedented challenge to the usual understanding of reality.

This new fact of nature was revealed in a series of experiments which tested predictions as follows. The predictions were proposed in a theorem developed by the Irish theoretical physicist John S. Bell in response to a number of questions raised by Albert Einstein and others in $1936 .{ }^{20}$ In later years a series of landmark experiments was conducted by the physicists Alain Aspect, et al. in 1982 and later Nicolaus Gisin, et al. in 1997. ${ }^{21}$ These revolutionary discoveries were derived directly from the quantum mechanics, of which veracity has been vindicated experimentally. In the Aspect experiments conducted at the University of Paris, correlations of linear polarizations of pairs of photons were measured at a distance between the two filters of thirteen meters. The results demonstrated that the photons "interacted" or "communicated" with one another instantaneously and simultaneously. This experiment led to the revelation that physical reality is indeed not local, but rather nonlocal. Nadeau and Kafatos concluded that this result provided unequivocal evidence that the "single" wave hypothesis may be false and that Einstein's view of "locality" realism does not hold in a quantum mechanical universe. ${ }^{22}$ Fifteen years later, Nicholas Gisin and colleagues at the University of Geneva extended the earlier landmark experiment of Aspect, using entangled photons (light particles) originated under certain conditions. They traveled in opposite directions to detectors located about seven miles apart in order to enable simple but instantaneous communication. These experiments conclusively demonstrated the nonlocality to a photon that might as well be halfway across the universe. No signal traveling at the speed of light could be presumed to carry information between the analyzers. Nadeau and Kafatos view that this discovery is said to be "the most momentous in the history of science". 23

The implications of this unveiling of nonlocality may extend beyond the domain of the physical sciences and have the potential to transform current conceptions of reality beyond any known previous theories or ideas documented in the history of humanist-social sciences. The results of these experiments suggest that all of physical reality consists of a single quantum system that responds en masse to further interactions. The quanta that make up our bodies could be as much a part of this unified system as the photons in the Aspect and Gisin experiments. Thus, nonlocality or non-separability in these experiments as the factual condition in the entire universe can translate such single quantum system into one of nonduality. A revolutionary look at the implications of this fact of nature, nonlocality to nonduality, presents a new scientific epistemology and reaches deep into one of the most intimate aspects of humanistic studies, that is, religiosity.

It is intriguing to note that this new revelation and subsequent understanding of the fundamental relationship between the part and the whole as has been disclosed in quantum mechanics conforms precisely to the concept of "one is all and all is one" and "unhindered mutual interpenetration of phenomena to phenomena" in Buddhism. The former indicates an

\footnotetext{
${ }^{20}$ John S. Bell, "On the Einstein-Podolsky-Rosen-Paradox", Physics 1, (1964), pp. 195-200.

21 Wolfgang Tittel, Juergen Brendel, Thomas J.Herzog, Hugo Zbinden, and Nicolas Gisin, "Experimental demonstration of quantum-correlations over more than 10 Kilometers", in Physical Review A57/5 (1998), pp. 3229-3232.

${ }^{22}$ Robert Nadeau, and Menas Kafatos, The Non-Local Universe, pp. 77-80.

${ }^{23}$ Ibidem, p. 3.
} 
expression of the essential unity of all things; a tenet of the Huayan and Tiantai schools and the latter characterizes a non-obtruction among individual phenomena, an important concept in Huayan philosophy.

Virtually everything in the immediate physical environment is said to be made up of quanta that have been interacting with other quanta in a single quantum state. All particles in the history of the cosmos may have interacted with other particles in the manner revealed by the Aspect experiments. "Quantum entanglement" is the term used to describe the manner in which particles of energy/matter can become correlated predictably to interact with each other regardless of how far apart they are. It implies that particles, separated by incredible distances, are able to interact with each other immediately in a communication that is not limited to the speed of light. It further suggests that no matter how far the distance between the correlated particles, they remain entangled as long as they are isolated. Entanglement is presumed to be a real phenomenon, that is, it is the nonlocal interaction of objects that are separated in space. Although Einstein called it "spooky action at a distance," a number of physicists demonstrated and verified it repeatedly through experimentation. ${ }^{24}$ They observed that entanglement could not be an illusion created by any speed-of-light communication between particles, or certain photons. ${ }^{25}$

Earlier Anton Zeilinger pointed at the quantum entanglement as nonlocal connectedness of two particles, in which under certain circumstances two particles remain one system even if separated by a very large distance. ${ }^{26}$ This implies that in a fundamental sense, they are not really separated at all. In the latest effort to explore this phenomenon, physicists led by Zeilinger at the University of Vienna along with nineteen other colleagues in China, Germany and USA developed a new version of the Bell test in February 2017. They have used light, emitted from two stars in the Milky Way around 600 years ago, to bolster the case for Einstein's "quantum spookiness." Their results have verified a level of correlation that supports "action at a distance". ${ }^{27}$ According to physicist N. David Mermin quantum entanglement grows exponentially with the number of particles involved in the original quantum state; indeed, there is no theoretical limit on the number of these entangled particles. ${ }^{28}$ If this is true, objects in the universe on a very basic level remain in contact with one another over any distance in no time in the absence of the transfer of energy or information: metaphorically a vast web of particles. However, the mechanism, which maintains such a connectedness, cannot as yet be fully explained by any theory.

Strikingly, this fact of nature points intuitively to Amitābha Buddha's image of "Infinite Light and Infinite Life." The term "Indra's net" which is said to adorn the palace of the god Indra is appropriate here as it refers to the idea that each intersection of the net holds

\footnotetext{
${ }^{24}$ George Musser, Spooky Action at a Distance, Scientific American, New York, 2015, p. 9. See also Max Born, and Albert Einstein, Born-Einstein Letters, 1916-1955: Friendship, Politics and Physics in Uncertain Times, (trans.), by Irene Born, Palgrave Macmillan. New York, 2005, p. 155.

${ }^{25}$ Lynden K. Shalm et al., "Strong Loophole-Free Test of Local Realism", in Phys. Rev. Lett. 115 (2015), 250402. B. Hensen et all., "Loophole-free Bell inequality violation using electron spins separated by 1.3 kilometres", Nature 526 (2015), pp. 682-686. Marissa Giustina et al., "Significant-Loophole-Free Test of Bell's Theorem with Entangled Photons", in Phys. Rev. Lett. 115 (2015), 250401.

${ }^{26}$ Anton Zeilinger, "Experiment and Paradox in Quantum Physics", in Arthur Zajonc, (ed.), The New Physics and Cosmology: Dialogues with the Dalai Lama, Oxford University Press, NY., 2004, p. 24.

${ }^{27}$ Johannes Handsteiner et al., "Cosmic Bell Test: Measurement Settings from Milky Way Stars", in Phys. Rev. Lett. 118 (2017), 060401.

${ }^{28}$ N. David Mermin, "Extreme Quantum Entanglement is a Superposition of Macroscopically Distant States", in Physical Review Letters 65-15, (1990), pp. 1838-1840.
} 
a reflecting jewel which mirrors all the other countless jewels in the net. This term is frequently employed as a metaphor for the interrelation or mutual inclusiveness of all phenomena. The discovery that nonlocality is indeed a fact of nature may not produce immediately a drastic change in human daily life, but it may, at the least, warrant significant revisions to the current scientific world-view. The impact on humanist-social studies may indeed revolutionary in the years to come. As Henry P. Staff stated, nonlocality could be the "most profound discovery in all of science.", 29

As nonlocality emerges as a property of the entire universe, Nadeau and Kafatos have concluded, "An undivided wholeness may exist on the most primary and basic level in all aspects of physical reality". ${ }^{30}$ The reality that exists between the space-like separated regions appears to be an indivisible whole. Interestingly, before the results of the Aspect and Gisin experiments were known, most physicists were convinced that they would completely restore a certain faith in the classical or Einsteinian epistemology and in the doctrines of positivism, reductionism and objectivism. Now these new understandings of nonlocality and the new epistemology of science need to be incorporated into humanity studies.

\section{FROM NONLOCALITY TO NONDUALITY AND WHOLENESS}

Intuitively, the concept of nonlocality in quantum physics forms a link to that of nonduality, which implies non-separation and fundamental oneness in the philosophical and religious perspectives. Specifically, Buddhists claim that all distinctions are the imaginary products of thought and language superimposed on a fundamentally nondual reality. Using powerful contemplative methods of first-person investigation, Buddhists have focused on the direct experience of the observing mind itself. Strangely enough, this has been known and accepted by quantum physics in the form of its "observer effect," a measurement problem, which is encapsulated lucidly by the quantum physicist Goswami: "An observation converts the objects from waves of quantum possibilities into particles of actualities ('collapse') in the observer's consciousness". ${ }^{31}$ Physicalist-reductionist thinking about consciousness cannot adequately explain the observer effect, as it is a logical paradox. The solution of the measurement problem is to conceive of the "collapse" as the outcome of choice by a nonlocal consciousness. One of the key paradoxes of quantum physics is that when light travels through space, it seems to travel as a wave, but when it is detected, it appears as a particle. Building on the idea of the observer effect, Goswami proposes a new paradigm shift in that the observer effect forces a movement from the primacy-of-matter to a new paradigm: the primacy-of-consciousness. In his "The Scientist, The Buddha and God,"32 Goswami sets forth his theory of Quantum Activism, which posits the idea of changing ourselves and societies in accordance with the transformative and revolutionary message of quantum physics. This is a new paradigm within science, one of a consciousness-based reality. Goswami suggests that quantum physics relays three transformative messages. First, consciousness is the ground of all being, and all objects of experience are quantum possibilities for consciousness to choose from. Second, if one chooses from what is known, that is, what is conditioned from prior experiences, one is choosing from the ego-

\footnotetext{
${ }^{29}$ Henry P.Staff, “Are superluminal connections necessary?” in Nuovo Cimento 40B (1977), p. 191.

${ }^{30}$ Robert Nadeau, and Menas Kafatos, The Non-Local Universe, p. 4.

${ }^{31}$ Amit Goswami, How Quantum Activism Can Save Civilization, Hampton Roads Publishing Company, Inc., Charlottesville, VA., 2011, pp. 14, 38-39, 49.

32 Amit Goswami, "The Scientist, the Buddha and God", An Invitation to Quantum Activism Science and Nonduality Conference, San Rafael CA., 2009.
} 
consciousness. But if one chooses what is unknown, or what is unmanifested from prior experiences, one is choosing from what spiritual traditions call "God-consciousness," or "quantum consciousness" in scientific language. Choosing from God-consciousness requires quantum leaps (movement from point $\mathrm{A}$ to point $\mathrm{B}$ without going through intermediate steps), nonlocality (signal-less communication), and tangled hierarchy (causal relationships of circularity). The third message of quantum physics refers to the evolution of consciousness, noting the movement from the current preoccupation with the rational mind to an intuitive mind that values the archetypes, such as good, beauty, truth, justice, and love. This gives one the ability to process the meaning of his/her lives through these archetypes. In the wake of the findings of quantum mechanics, Goswami adopts the phrase "Opto, ergo sum" (I choose, therefore I am) instead of Descartes' "Cogito, ergo sum" (I think, therefore I am). ${ }^{33}$ However, the concept of illusion in Buddhism moves beyond even Goswami's "Godconsciousness" or "quantum consciousness." Doctrine of emptiness or voidness in Buddhism refers to the understanding that all existence is based solely on dependent origination, that is, our perception of reality is simply an illusion; all phenomena in the universe are mere projections, having no-Self and impermanence, and thus this world has no separate or independent core of essence. As mentioned earlier, Quantum physicists describe "neither existence" while Nagarjuna emphasizes "nor non-existence" simultaneously. From the Buddhist's perspective of neither existence nor no-existence, also existence and nonexistence in situ, we venture to redefine Goswami's "Opto, ergo sum" more precisely as "Subiungo, ergo sum" (I attach, therefore I am). This is to highlight a significance of attachment in Buddhism.

Although both disciplines indicate the distinctive characteristics of the observer effect in the investigation of the nature of the mind, Buddhism emphasizes the idea of nonduality in the context of "neither one, nor two." This can be intuitively understood if one perceives that in external reality two elements of dichotomy appear separated and mutually exclusive, but in actuality represent two, perhaps multiple, facets of a single underlying whole. Regarding this, a thirteenth century Chan master, Zuigan, practiced Chan Buddhism in a unique way:

'Every day Zuigan used to call to himself, 'Master!' and would answer, 'Yes!' Again, he would call, 'Thoroughly awake! Thoroughly awake!' and he would answer, 'Yes! Yes!' 'Don't be deceived by others, and any day or any time.' 'No! No!',34.

The reason why those who are searching for the truth cannot realize it is because they perceive relative consciousness only and take it entirely for a fixed entity. Perhaps modern intellectuals need to find a real master within themselves, just as Zuigan used to call himself in order to evoke a religious insight, which can transcend ordinary time and space. Buddhists claim that beyond the ordinary perception, memory, and thought there is a pure awareness, the inner experience of consciousness, namely "awareness of awareness" or the "selfwitnessing aspect" which implies the self-authenticating aspect of cognition. It refers to the witnessing of the functioning of the subjective aspect. Buddhism has described this undifferentiated consciousness as being the ultimate state of bliss or nirvana. However, such an ultimate state of bliss is said to be ineffable; if any seeker wants to explain it, a Chan master would say that the seeker inevitably goes wrong even before one opens his/her mouth. The essence of teaching is construed as utterly indescribable. However, the central

\footnotetext{
${ }^{33}$ Amit Goswami, The Self-Aware Universe, Putnam Book NY., 1993, p. 107.

${ }^{34}$ Kōun Yamada, (trans.), 'Zuigan Calls Himself 'Master', in Gateless Gate, Mumonkan, Center Publications, Los Angeles, CA., 1979, pp. 67-71.
} 
challenge to understanding such indescribable nonduality may be that once it has been named or defined, then paradoxically another duality can be created. It is just like that at the very moment one observes the wave state, quantum reality does collapse and the wave becomes a particle. Even the statement "all things resolve into one" creates a distinction between "one" and "not-one"! As the famous Chan master Chao Chou claims, "Ten thousand dharmas converge to One, where would One return to?" Chao Chou is like sparks struck from stone, like the brilliance of a flash of lightning. If one goes to the words to discriminate, $\mathrm{s} /$ he is mistakenly abiding by the zero point of a scale. ${ }^{35} \mathrm{In}$ Buddhism, the truth is often classified as both ultimate and relative; ultimate truth is the reality when perceived from the viewpoint of the Buddha, as opposed to conventional or relative truth of the phenomenal world, which is perceived from a worldly standpoint. Thus, nonduality is pertinently situated in the Middle Way of Buddhism, which is expressed as neither different nor the same, just as Bohm described "The two truths are one entity, but different isolates". 36 Similarly, quantum reality consists of an inaccessible wave-particle dualism; the waves and particles themselves can transmute into each other [neither one nor two]. With this understanding, it may be sufficient to say that the essential feature of quantum mechanics corresponds figuratively to the wisdom aspect (Mahāsthāmaprāpta) of Amitābha Buddha. In this regard, śunnyatā and quantum reality agree on one of the basic concepts of reality principle.

However, once a religious insight is attained in Buddhism, the wisdom obtained should naturally be able to incorporate in situ the compassion aspect (Avalokiteśvara) of Amitābha Buddha as well. Wisdom and compassion are just like two sides of a coin. It can be said that as wisdom can be understandable, it is therefore learnable. When wisdom is thoroughly understood and experienced, can compassion surface naturally, just as the moon can be revealed itself in a clear, still lake. True Suchness, or Bhütatathatā in Buddhism, which is the ultimate truth as the state of things as they really are, is manifested sufficiently in both wisdom and compassion, which are complementary like the particle and the wave, as stated by Bohr. However, the element of compassion has not heretofore been incorporated in science, probably due to its being considered as non-objective and therefore non-scientific from the Cartesian-Newtonian perspective. Further, it is highly unlikely that compassion may be seen as complementary to wisdom any time soon by the scientific world. The missing link here is religious insight, which is a natural byproduct of an experienced wisdom, to be acquired not necessarily by knowledge, but rather consequent to a rigorous practice. In the current trend, however, a fundamental limitation exists in that a rigorous practice is considered to stay outside of the classical, scientific intellectual domain. How can modern intellectuals with a scientific mind-set regard it, then?

\section{MEDITATION AS PRESCRIBED FOR MODERN INTELLECTUALS}

There is a general consensus that modern intellectuals are often inundated by a flood of information, which at times threatens their capacity to maintain a healthy level of sanity. Humans, more than any other beings on Earth, have an innate ability to process an enormous amount of information, and to consequently create all kinds of conceptions within a given space-time dimension. Unfortunately, however, we are often motivated and driven by limitless greed, anger, and ignorance, whether explicitly or implicitly. This fatefully

\footnotetext{
${ }^{35}$ Thomas and JC. Cleary, (trans.), The Blue Cliff Record, Vol 2, Shambhala, Boulder, CO., 1977, pp. 318-322.

${ }^{36}$ Guy Newland, The Two Truths. Ithaca, Snow Lion Publications, New York, 1992, pp. 59-75.
} 
compelling process may tend to make a certain susceptible people vulnerable to a host of afflictions, such as attention deficit hyperactive disorder (ADHD), obsessive and compulsive reaction, depression, aggressive behaviors and so forth. Unfortunately, a number of publications reveal that this trend is worsening. The number of children diagnosed with ADHD continues to climb, according to new data from the Centers for Disease Control and Prevention. ${ }^{37}$ In $2011,11 \%$ of children/adolescents aged 4 to 17 years received an ADHD diagnosis (6.4 million children). There has been a $42 \%$ increase in the number of reported cases since 2003. More than two-thirds of those were taking medication. According to the IMS Health report in 2013, the antipsychotic drug Abilify (aripiprazole) racked up the highest number of sales among the top 100 selling drugs in the U.S., with profits of nearly $\$ 6.4$ billion. Abilify is known to be prescribed to treat schizophrenia, depression, bipolar disorder, and other maladies. ${ }^{38}$ This reflects the increasing burden being placed on the U.S. health care system. Efforts to further understand diagnostic and treatment patterns are certainly warranted. What are the alternatives?

Among noted quantum physicists, David Bohm of Princeton University uniquely indicated that insight is required to end the illusion originating in our thought; the self and the world are broken into fragments. ${ }^{39}$ Bohm defines our everyday world of space, time and causality as the explicate order, whereas underlying this everyday world is an interconnected, or the implicate order. Given the unbroken wholeness of the implicate order, Bohm asks why our thought is so dominated by fragmentation. He states as follows:

\begin{abstract}
“... fragmentation is continually being brought about by the almost universal habit of taking the content of our thought for 'a description of the world as it is' (Ibid, p. 4). Our fragmentary way of thinking, looking, and acting, evidently has implications in every aspect of human life (Ibid., p. 20). So fragmentation is in essence a confusion around the question of difference and sameness (or Oneness), but the clear perception of these categories is necessary in every phase of life (Ibid., p. 21)".
\end{abstract}

Bohm views this illusion as somewhat locality-duality-nonwholeness based, which in Buddhist terms is remarkably similar to the concept of moha (ignorance, delusion), one of the three poisons: lobha, greed; dosa, hatred; moha, ignorance, as posited by the Buddha. $\mathrm{He}$ argues that meditation may be necessary in order to produce an insight that can break the illusion. He writes:

"[Meditation] is particularly important because, as has been seen, the illusion that the self and the world are broken into fragments originates in the kind of thought that goes beyond its proper measure and confuses its own product with the same independent reality. To end this illusion requires insight, not only into the world as a whole, but also into how the instrument of thought is working (Ibid., p. 32)".

How can one obtain such insight? Among the various ways of inducing it, Amitābha recitation, for example, has been highly recommended and practiced in the Pure Land Buddhist tradition. According to that tradition, by the power of his vows Amitābha has made it possible for all who call upon him to be reborn into the Pure Land. Depending on how one interprets this, the Pure Land may not necessarily be located out there objectively, but rather can be revealed here and now from the quantum perspective. Incessantly calling the name Amitābha will help concentrating one's wandering attention to this one point, and creating a

\footnotetext{
37 Susanna N. Visser et al. "Trends in the Parent-Report of Health Care Provider-Diagnosed and Medicated Attention-Deficit/Hyperactivity Disorder: United States, 2003-2011”, in Journal of the American Academy of Child \& Adolescent Psychiatry 53-1, (2014), pp. 34-46.

${ }^{38} \mathrm{http} / / / \mathrm{www} . w e b m d . c o m / c h o l e s t e r o l-m a n a g e m e n t / n e w s / 20131101 /$ crestor-is-top-selling-drug?printing=true

${ }^{39}$ David Bohm, Wholeness and the Implicate Order, Routledge \& Kegan, London, 1980, pp. 186-190.
} 
continuous stream of consciousness. Thus, the recitation can be evocative of both wisdom, which is based on nonlocality-nonduality-wholeness, and its complementary counterpart, compassion. When these two elements are amalgamated into Oneness, it will lead to the unique experience at the root of religiosity of the "wondrous existence of true emptiness" and "neither one, nor two."

In this regard, we prudently propose a breakthrough invitation to Amitābha Buddha. By utilizing a similar vein of repetitive pattern and concentrating one's wandering attention to one point, Amitābha recitation can be a beneficial and effective practice for today's intellectuals. This can be accomplished either through direct chanting or by listening to chanting. ${ }^{40}$ One may argue that this may sound apologetic, however, it can become an intense reminder of the "Infinite Light and Infinite Life," symbolizing wisdom and compassion, respectively, which exist within all of us. It is not necessarily of apologetic nature at least from a rational perspective. With devoted practice, the repercussion of the name Amitābha can be heard while awake or asleep, creating a continuous stream of consciousness, which the fourteenth century Korean Seon master Naong considered essential to the attainment of enlightenment. ${ }^{41}$ This means that the practitioner must persist in his/her process of inward attention without interruption and with full one-pointed concentration throughout the three states of wakefulness, dream, and deep sleep. At this stage, it can be said that Amitābha Buddha and possibly modern science can meet at the very core of religiosity, an enlightenment.

\section{CONCLUSION}

The dialogue between religion and science is ongoing. Discussion between Buddhism and science has been actively intensifying in a small group of Buddhologists and scientists, notably quantum physicists. The intellectual search for ultimate truth reveals a complementary synergy between Buddhism and modern science. We have presented the subject of Amitābha Buddha as it relates to quantum physics -- an approach which may seem rather bold, as Amitābha Buddha represents the religious practice of meditation, particularly the use of a mantra stemming from a faith-based sect, whereas quantum physics is an exceptionally precise science with an accuracy of one part in 100 billion. This article develops and employs a novel conceptual approach to address a broader understanding and acceptance of modern science for scholars of religion. We investigate the concept of nonlocality to introduce the non-scientific subject of Amitābha Buddha to present-day intellectuals. As this attempt is unprecedented within the scope of academia, it may raise more questions than answers, requiring deeper study and revealing the necessity for more penetrating insights, both scientifically and religiously. To facilitate this goal, we have discussed a branch of Buddhism, the Pure Land sect, pointing out its links with modern science in terms that may be easier for modern intellectuals to accept, assimilate and integrate into their understanding. We argue that the concept of nonlocality, with its extension into a sequence of nonlocality-nonduality-wholeness, enables Amitābha's wisdom and compassion to fit reasonably within the framework of modern science.

\footnotetext{
${ }^{40}$ Amitābha Buddha Name Recitation, http://www.amtb-usa.org/index.htm, Amitābha Buddhist Society of USA.

${ }^{41}$ Naong was the founder of the Lin-chi tradition of Hwadu Seon in Korea, and introduced the criteria of Three Gates, in order for a Buddhist practitioner of meditation to have one's experience of enlightenment. This had been brought up recently and strongly emphasized by the late Supreme Patriarch, Seong Cheol of the Korean Buddhist Jogye Order.
} 
Further, it bridges the chasm between the elements of wisdom and compassion, which involves an issue of religiosity. Amitābha Buddha can now reappear based on a reasonably tested scientific principle, specifically, the quantum model of the mind. Perhaps this approach can help reconcile the scientific assumption or belief with a religious faith and open a new theoretical window into Einstein's "religious feeling of a special kind" or an enlightenment of the Buddhist kind.

After all among various ways of inducing religious insight, a mantra practice Amitābha recitation - may be a reasonable option for intellectually oriented modern readers as well as religious practitioners. In this regard, it is to be remembered that although the Buddhologist need not necessarily be a Buddhist practitioner, there is certainly nothing scientifically invalid with him/her choosing to be one. As Einstein (1941) states in his essay, Science and Religion:

"I cannot conceive of a genuine scientist without that profound faith. The situation may be expressed by an image: science without religion is lame, religion without science is blind". 42

\section{BIBLIOGRAPHY:}

[1] Ahn, Dong Rim, (trans.), Sin Yeok Byeok Ahm Rok, Hyeonahmsa, Seoul, Korea, 1978.

[2] Aspect, Alain, Dalibard, Jean, and Roger, Gérard, "Experimental Tests of Bell's Inequalities Using Time-varying Analyzers", in Physical Review Letters 49, (1982), pp. 1804-1807.

[3] Bell, John S., "On the Einstein-Podolsky-Rosen-Paradox", Physics 1, (1964), pp. 195-200.

[4] Bohm, David, Wholeness and the Implicate Order, Routledge \& Kegan, London, 1980.

[5] Bohr, Niels, The Philosophical Writings of Niels Bohr, Ox Bow Press, Woodbridge, CT.,1987.

[6] Born, Max, and Einstein, Albert, Born-Einstein Letters, 1916-1955: Friendship, Politics and Physics in Uncertain Times, (trans.), by Irene Born, Palgrave Macmillan. New York, 2005.

[7] Buswell, Robert E., Jr., and Lopez, Donald S., The Princeton Dictionary of Buddhism, Princeton University Press, Princeton, NJ., 2014.

[8] Cleary, Thomas and JC., (trans.), The Blue Cliff Record, Vol 2, Shambhala, Boulder, CO.,1977.

[9] The Dalai Lama, Benson, Herbert, Thurman, Robert A.F., Gardner, Howard E., and Goleman, Daniel, MindScience: An East-West Dialogue, Wisdom Publications, Boston, MA., 1991.

[10]Einstein, Albert, "Science and Religion" in Transactions of the First Conference on Science, Philosophy and Religion, A Symposium, published by the Conference on Science, Philosophy and Religion in Their Relation to the Democratic Way of Life, Inc., New York, 1941.

[11] Giustina, Marissa, Versteegh, Marijn A. M., Wengerowsky, Sören, Handsteiner, Johannes,

[12] Hochrainer, Armin, Phelan, Kevin, and Steinlechner, Fabian et al., "Significant-Loophole- Free Test of Bell's Theorem with Entangled Photons”, in Phys. Rev. Lett. 115 (2015), 250401, doi:https://doi.org/10.1103/PhysRevLett.115.250401.

[13] Goswami, Amit, The Self-Aware Universe, Putnam Book, New York, 1993.

[14]_, The Scientist, the Buddha and God. An Invitation to Quantum Activism Science and Nonduality Conference, San Rafael CA., 2009.

[15]_. How Quantum Activism Can Save Civilization, Hampton Roads Publishing Company, Inc., Charlottesville, VA., 2011.

[16] Hakeda, Yoshito S., (trans.), The Awakening of Faith; Attributed to Aśvaghosha, Columbia University Press, New York \& London, 1967.

[17] Handsteiner, Johannes, Friedman, Andrew S., Rauch, Dominik, Gallicchio, Jason, Liu, Bo,

[18] Hosp, Hannes, and Kofler, Johannes et al., "Cosmic Bell Test: Measurement Settings from Milky Way Stars", in Phys. Rev. Lett. 118 (2017), 060401.

[19]Hawking, Stephen and Penrose, Roger, The Nature of Space and Time, Princeton University Press, Princeton \& Oxford, 1996.

${ }^{42}$ Albert Einstein, "Science and Religion" in Transactions of the First Conference on Science, Philosophy and Religion, A Symposium, the Conference on Science, Philosophy and Religion in Their Relation to the Democratic Way of Life, Inc., New York, 1941. 
[20] Heisenberg, Werner, Physics and Philosophy: The Revolution in Modern Science, Harper \& Row, Publishers, NY, 1958.

[21]Hensen, B., Bernien, H., Dre'au, A. E., Reiserer, A., Kalb, N., Blok, M. S., and Ruitenberg, J. et al., "Loophole-free Bell inequality violation using electron spins separated by 1.3 kilometres", Nature 526 (2015), pp. 682-686, doi:10.1038/nature15759.

[22] Jammer, Max. Einstein and Religion: Physics and Theology, Princeton University Press, Princeton, NJ., 1944.

[23]Kim, Sung K. and Cho, Y.G., Modern Physics explains Ban Ya Sim Gyung, Bulgwang Publishing Co., Seoul, Korea, 2006.

[24] Marshall, Ian and Zohar Danah, Who’s Afraid of Schrödinger's Cat? William Morrow \&Co., NY., 1997.

[25] Maudlin, Tim, Quantum Non-Locality and Relativity, Blackwell, Malden, MA., 1994.

[26] Mermin, N. David, "Extreme Quantum Entanglement is a Superposition of Macroscopically Distant States", in Physical Review Letters 65-15, (1990), pp. $1838-1840$.

[27] Müller, F. Max, "The Larger Sukhāvatī-vyūha, Buddhist Mahāyāna Texts", in The Sacred Books of the East, Vol. xlix, (trans.) by Müller, F. Max, Dover Publications, Inc., Mineola, NY, 1969.

[28] Musser, George, Spooky Action at a Distance, Scientific American, New York, 2015.

[29] Nadeau, Robert and Kafatos, Menas, The Non-Local Universe: The New Physics and Matters of the Mind, Oxford University Press, New York, 1999.

[30] Newland, Guy, The Two Truths, Ithaca, Snow Lion Publications, New York, 1992.

[31] Park, Sung B., Buddhist Faith and Sudden Enlightenment, SUNY Press, Albany, NY, 1983.

[32] Penrose, Roger, "Quantum Theory and Spacetime", in The Nature of Space and Time, (ed.), by Hawking, Stephen and Penrose, Roger, Princeton University Press, Princeton \& Oxford, 1996.

[33] Prebish, Charles S., Historical Dictionary of Buddhism; Historical Dictionaries of Religions, Philosophes, and Movements, The Scarecrow Press, Inc., Metuchen, N.J., \& London, 1993.

[34] Ramanan, K. Venkata, Nagarjuna's Philosophy: As Presented in the Maha-Prajnaparamita- Sastra, Motilal Banarsidass, New Delhi, India, 1966.

[35] Shalm, Lynden K., Meyer-Scott, Evan, Christensen, Bradley G., Bierhorst, Peter, Wayne, Michael A., Stevens, Martin J. and Gerrits, Thomas et al., "Strong Loophole-Free Test of Local Realism", in Phys. Rev. Lett. 115 (2015), 250402.

[36] Staff, Henry P., "Are superluminal connections necessary?" in Nuovo Cimento 40B (1977), pp. 191-205.

[37] Tittel, Wolfgang, Brendel, Juergen, Herzog, Thomas J., Zbinden, Hugo, and Gisin, Nicolas, "Experimental demonstration of quantum-correlations over more than 10 Kilometers", in Physical Review A57/5 (1998), pp. $3229-3232$.

[38] Visser, Susanna N., Danielson, Melissa L., Bitsko, Rebecca H., Holbrook, Joseph R., Kogan, Michael D., Ghandour, Reem M., and Perou, Ruth et al., "Trends in the Parent-Report of Health Care ProviderDiagnosed and Medicated Attention-Deficit/Hyperactivity Disorder: United States, 2003-2011", in Journal of the American Academy of Child \& Adolescent Psychiatry 53-1, (2014), pp. 34-46.

[39] Yamada, Kōun, (trans.), "Zuigan Calls Himself 'Master'”, in Gateless Gate, Mumonkan, Center Publications, Los Angeles, CA., 1979.

[40]Zeilinger, Anton, "Experiment and Paradox in Quantum Physics", in Arthur Zajonc, (ed.), The New Physics and Cosmology: Dialogues with the Dalai Lama, Oxford University Press, NY., 2004, p. 24 